\title{
Prevalence and Associated Factors of HIV and CMV Co-Infection in Tianjin, China
}

\author{
Bei Jiang ${ }^{1,2 \#, ~ R u i ~ S u}{ }^{1,2 \#}$, Defa Zhang ${ }^{1}$, Liying Gao', Ping Ma1* and Wei $\mathrm{Lu}^{1,2}$ \\ ${ }^{1}$ Tianjin Second People's Hospital, Tianjin, China \\ ${ }^{2}$ Tianjin Institute of Hepatology, Tianjin, China \\ \#These authors contributed equally to this work
}

\begin{abstract}
The prevalence and associated factors of human immunodeficiency virus (HIV) and cytomegalovirus (CMV) coinfection in patients starting antiretroviral therapy (ART) in Tianjin, China are under-studied. We measured CMV DNA in plasma specimens of $1347 \mathrm{HIV}$-infected patients. T-cell dynamics were measured by flow cytometry. A total of 1347 patients participated in this study. 1288 (95.6\%) were male. The median age was 36. Both CMV positive and CMV negative groups were similar apart from the higher proportion of homosexual/bisexual HIV transmission in CMV negative group and the older age in CMV positive group. According to the duration of first-line ART, we did not observe a significant difference between CMV positive and CMV negative groups. CD4 counts and CD4 nadir counts are independent risk factors for the prevalence of CMV in HIV infected patients. We found a high prevalence of CMV $(12.8 \%)$ in Tianjin HIV-infected patients starting ART. CMV serological status should be taken into account when measuring the effectiveness of antiretroviral therapy on immune restoration.
\end{abstract}

Keywords: Cytomegalovirus; HIV; Co-infection; CD4; Tianjin

Abbreviations: CMV: Cytomegalovirus; HIV: Human Immunodeficiency Virus; ART: Antiretroviral Therapy

\section{Introduction}

Human cytomegalovirus (CMV) is a common opportunistic pathogen associated with inflammation and increased mortality, which is highly prevalent among HIV-infected individuals [1]. In particular, asymptomatic CMV co-infection is ubiquitous in HIV infected individuals. Retinitis, pneumonia and colitis are the most commonly reported CMV manifestations in HIV-infected individuals [2]. Persistently low levels of CMV replication could contribute to incomplete recovery of the CD4/CD8 ratio in people who started ART during the earliest phases of HIV infection [3]. The incomplete recovery of CD4/CD8 ratio is closely associated with increased mortality and morbidity during HIV infection [4]. Furthermore, CMV triggers persistent immune activation and inflammation and is responsible for a sizable proportion of the entire memory T-cell response [5]. Meanwhile, Most HIV-infected individuals undergo intermittent outbursts of CMV replication even during ART, which might contribute to the continuous expansion of CD8 T cell compartment [6]. HIV infection affects CD4 and CD8 $\mathrm{T}$ cells by a loss of CD4 $\mathrm{T}$ cells and a low ratio between $\mathrm{CD} 4$ and $\mathrm{CD} 8 \mathrm{~T}$ cells. Low $\mathrm{CD} 4 / \mathrm{CD} 8$ is associated with poor clinical outcomes, T-cell dysfunction and increased inflammation [7].

ART has improved the conditions of those living with HIV. From the immunological aspect, ART enhances immune reconstitution in HIV-infected individuals leading to an enhanced protection against pathogens [8]. ART has been shown to have a wide array of targets and functions, including acting as an anti-tumor, antibacterial, anti-fungal, antimalarial, anti-Severe acute respiratory syndrome and anti-influenza agent [9].

Between 2004 and 2014, there were 2775 cases newly diagnosed case of HIV in Tianjin [10]. Similar to large cities with well-established populations like New York in the USA and Beijing in China, the rapid growth of the HIV-infected population in Tianjin over the past decade has drawn much attention to Tianjin. In this study, we aimed to investigate the prevalence of HIV and CMV co-infection and its associated factors in Tianjin. We have conducted a cross-sectional study based on individual's diagnosed HIV positive between January 2015 and December 2016. To the best of our knowledge, this is the first study to explore the prevalence of HIV and CMV co-infection and its associated factors in Tianjin.

\section{Materials and Method}

\section{Ethics statement}

This study was approved by the human research ethics committee of Tianjin the second people's hospital. This study used data of anonymized patients obtained from routine practice and from stored serum samples.

\section{Study subjects}

Tianjin the second people's hospital, the AIDS clinical center of North China, was established in 1920 . The study population was HIV infected patients who first visited our hospital between January 2015 and December 2016. There were 1347 HIV-1 infected persons finished this study.

\section{Measurements}

This study is a retrospective, observational analysis from Tianjin the second people's hospital. Social demographics variables were collected by a structured interview conducted by a clinical nurse on

*Corresponding author: Ping Ma, M.D., Associate Professor, Department of Infection Center, The Second People's Hospital, 75 Sudi Rd, Nankai, Tianjin, 300192, China, Tel: 8602227426301; Fax: 8602227426301; E-mail: mapingtianjin@163.com

Received April 02, 2018; Accepted May 11, 2018; Published May 18, 2018

Citation: Jiang B, Su R, Zhang D, Gao L, Ma P, et al. (2018) Prevalence and Associated Factors of HIV and CMV Co-Infection in Tianjin, China. J AIDS Clin Res 9: 767. doi: 10.4172/2155-6113.1000767

Copyright: (C) 2018 Jiang B, et al. This is an open-access article distributed unde the terms of the Creative Commons Attribution License, which permits unrestricted use, distribution, and reproduction in any medium, provided the original author and source are credited. 
Citation: Jiang B, Su R, Zhang D, Gao L, Ma P, et al. (2018) Prevalence and Associated Factors of HIV and CMV Co-Infection in Tianjin, China. J AIDS Clin Res 9: 767. doi: 10.4172/2155-6113.1000767

Page 2 of 5

the first visit. This interview concerned sex, age, route of transmission, confirmed time of HIV and the time of ART initiation. HIV-1viral load, CMV viral load, CD4 cell count, hepatitis C antibody and hepatitis B surface antigen (HBsAg) tests are performed routinely for each patient in our hospital, so this information was gathered. The patient visited our hospital at least every three months.

\section{Statistical analysis}

Statistical analyses were performed in SPSS 19.0. All statistical tests were 2 -tailed and a P value of less than 0.05 was considered as significant. Continuous variables were described by means and corresponding standard deviations (SD), while categorical variable were described by frequency counts and corresponding percentages (\%). Invariable logistic regression analyses were performed to identify the bivariate relationships between the co-infection of HIV and CMV and social demographic characteristics. Multi-variable logistic regression analyses were performed to determine the independent contributions of each associated variable to HIV and CMV co-infection by simultaneously entering all the associated variables into the logistic regression model.

The minimum standards of reporting checklist contains details of the experimental design and statistics and resources used in this study.

\section{Results}

\section{Characteristics of the participants}

A total of 1481 eligible HIV-infected participants were enrolled in this study. 1407 (95.0\%) were of Han ethnicity, 859 (58.0\%) were married, $753(50.8 \%)$ had regular jobs or had completed higher education. Of the 1481 patients, a total of 1347 patients finished this study. These study patients were categorized into two group; patients with CMV infection $(n=173)$ and those without CMV $(n=1174)$. Table 1 displays the clinical characteristics of the study participants. $95.6 \%$ were males and the median age was 36 years, most were of Han ethnicity $(94.6 \%)$. Both groups were similar apart from the higher proportion of homosexual/bisexual HIV transmission cases in CMV negative group and the older members in CMV positive group. Ethnicity, marital status and educational level did not have a significant effect on CMV infection according to CMV serology.

\section{Prevalence of CMV co-infection in HIV-infected patients ac- cording to the time of first-line ART}

According to the time of first-line ART, we did not observe a significant difference between CMV positive and CMV negative groups, suggesting that the prevalence of CMV in HIV-infected patients with different duration of first-line ART is similar. The results are shown in Table 2.

\section{CD4T-cell dynamics after HIV suppression on first-line ART}

The kinetics of CD4 and CD4 nadir T cell counts in CMV positive and CMV negative patients are shown in Figure 1. The median circulating CD4 T cell number was significantly higher in HIV-infected CMV negative patients than in HIV-infected CMV positive patients $(\mathrm{P}<0.01)$. Our findings suggest CMV co-infection is a possible-driver of non-AIDS morbidities in treated HIV disease. As shown in Table 3,

\begin{tabular}{|c|c|c|c|c|c|}
\hline & All Patients $(n=1347)$ & $\begin{array}{l}\text { CMV Positive } \\
\quad(n=173)\end{array}$ & $\begin{array}{l}\text { CMV Negative } \\
\quad(n=1174)\end{array}$ & $t / x^{2}$ & P Value \\
\hline N (Male \%) & $1288(95.6 \%)$ & $159(91.9 \%)$ & $1129(96.2 \%)$ & 6.530 & 0.011 \\
\hline Age (years), Median (IQR) & $36(16-78)$ & $42(22-75)$ & $35(16-78)$ & -7.560 & $<0.001$ \\
\hline \multicolumn{4}{|l|}{ Transmission Risk Group } & 51.13 & $<0.001$ \\
\hline Heterosexual & $240(17.8 \%)$ & $50(28.9 \%)$ & $190(16.2 \%)$ & & \\
\hline Homo/bisexual & $924(68.6 \%)$ & $80(46.2 \%)$ & $844(71.9 \%)$ & & \\
\hline Intravenous drug use & $15(1.1 \%)$ & $1(0.6 \%)$ & $14(1.2 \%)$ & & \\
\hline Other & $19(1.4 \%)$ & $4(2.3 \%)$ & $15(1.3 \%)$ & & \\
\hline Unknown & $149(11.1 \%)$ & $38(22 \%)$ & $111(9.5 \%)$ & & \\
\hline \multicolumn{4}{|l|}{ Ethnicity } & 0.341 & 0.559 \\
\hline Han & $1274(94.6 \%)$ & $162(93.6 \%)$ & $1112(94.7 \%)$ & & \\
\hline Other minorities & $73(5.4 \%)$ & $11(6.4 \%)$ & $62(5.3 \%)$ & & \\
\hline \multicolumn{4}{|l|}{ Marital Status } & 0.318 & 0.573 \\
\hline Married & $791(58.7 \%)$ & $105(60.7 \%)$ & $686(58.4 \%)$ & & \\
\hline Unmarried & $556(41.3 \%)$ & $68(39.3 \%)$ & $488(41.6 \%)$ & & \\
\hline \multicolumn{4}{|l|}{ Educational Level } & 0.146 & 0.702 \\
\hline Higher education & $719(53.4 \%)$ & $90(52.1 \%)$ & $629(53.6 \%)$ & & \\
\hline Junior education & $628(46.6 \%)$ & $83(47.9 \%)$ & $545(46.4 \%)$ & & \\
\hline
\end{tabular}

Abbreviation: CMV: Cytomegalovirus; IQR: Inter-Quartile Range.

Table 1: Participant characteristics.

\begin{tabular}{|c|c|c|c|c|c|}
\hline Time on First-Line ART & All Patients ( $n=1347)$ & $\begin{array}{l}\text { CMV Positive } \\
(n=173)\end{array}$ & $\begin{array}{c}\text { CMV Negative } \\
(n=1174)\end{array}$ & 2 & P Value \\
\hline & & & & 6.925 & 0.140 \\
\hline$T \geq 2$ years & $100(7.4 \%)$ & $14(8.1 \%)$ & $86(7.3 \%)$ & & \\
\hline 1.5 years $\leq t<2$ years & $367(27.2 \%)$ & $50(28.9 \%)$ & $317(27.0 \%)$ & & \\
\hline 1 year $\leq t<1.5$ years & $298(22.1 \%)$ & $48(27.7 \%)$ & $250(21.3 \%)$ & & \\
\hline 0.5 year $\leq \mathrm{t}<1$ year & $279(20.7 \%)$ & $33(19.1 \%)$ & $246(21.0 \%)$ & & \\
\hline$t<0.5$ year & $303(22.5 \%)$ & $28(16.2 \%)$ & $275(23.4 \%)$ & & \\
\hline
\end{tabular}

Abbreviation: ART: Antiretroviral Therapy.

Table 2: Prevalence of CMV co-infection in HIV-infected patients according to the time on first-line ART. 
Citation: Jiang B, Su R, Zhang D, Gao L, Ma P, et al. (2018) Prevalence and Associated Factors of HIV and CMV Co-Infection in Tianjin, China. J AIDS Clin Res 9: 767. doi: 10.4172/2155-6113.1000767

Page 3 of 5
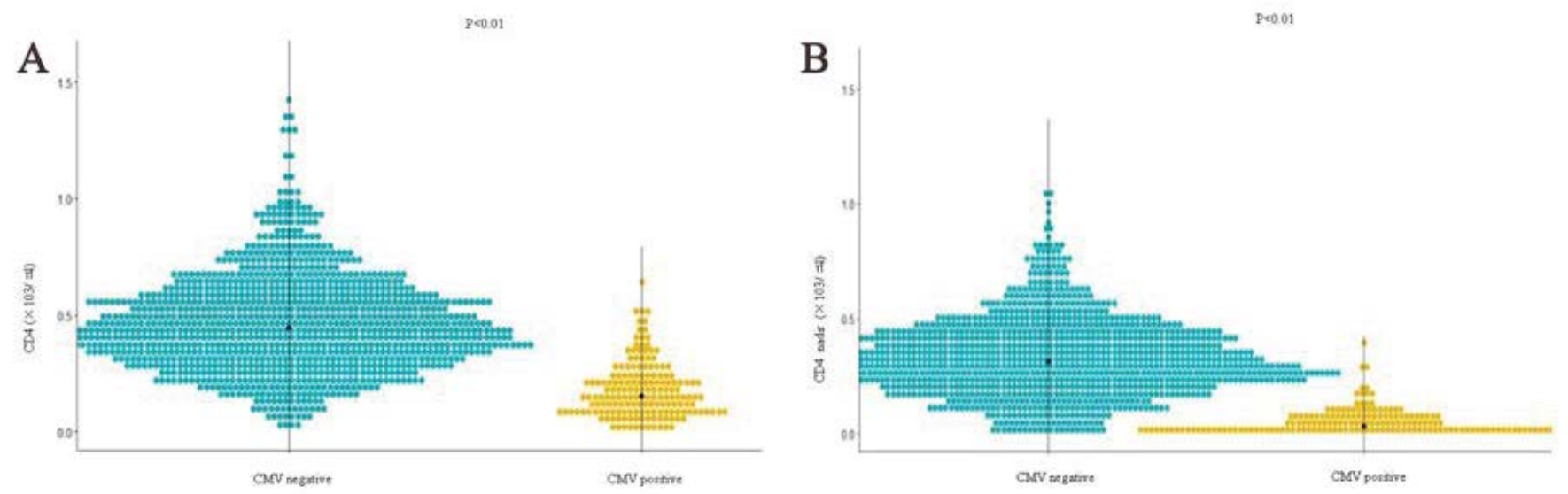

Figure 1: Absolute CD4 ${ }^{+}$T-cell and $\mathrm{CD}^{+}$nadir T-cell numbers between CMV negative and CMV positive group in HIV-infected individuals. The kinetics of CD4+ $\mathrm{T}$ cell count in CMV negative and CMV positive group (A).The kinetics of CD4 ${ }^{+}$nadir T cell count in CMV negative and CMV positive group (B) Significance was determined by using Mann-Whitney $U$ test.

\begin{tabular}{|c|c|c|c|c|c|}
\hline & All Patients $(n=1347)$ & $\begin{array}{c}\text { CMV Positive } \\
(n=173)\end{array}$ & $\begin{array}{c}\text { CMV Negative } \\
(n=1174)\end{array}$ & $x^{2}$ & P Value \\
\hline \multicolumn{4}{|l|}{ CD4 Cells/pl } & 450.302 & $<0.001$ \\
\hline$<100$ & $70(5.2 \%)$ & $52(30.1 \%)$ & $18(1.5 \%)$ & & \\
\hline $101-250$ & $222(16.5 \%)$ & $84(48.6 \%)$ & $138(11.8 \%)$ & & \\
\hline $251-350$ & $214(15.9 \%)$ & $20(11.6 \%)$ & $194(16.5 \%)$ & & \\
\hline$\geq 351$ & $841(62.4 \%)$ & $17(9.8 \%)$ & $824(70.2 \%)$ & & \\
\hline \multicolumn{4}{|l|}{ CD4 Nadir Cells/ $\mu \mathrm{l}$} & 744.238 & $<0.001$ \\
\hline$<100$ & $221(16.4 \%)$ & $152(87.9 \%)$ & $69(5.9 \%)$ & & \\
\hline $101-250$ & $334(24.8 \%)$ & $18(10.4 \%)$ & $316(26.9 \%)$ & & \\
\hline 251-350 & $315(23.4 \%)$ & $2(1.2 \%)$ & $313(26.7 \%)$ & & \\
\hline$\geq 351$ & $477(35.4 \%)$ & $1(0.6 \%)$ & $476(40.5 \%)$ & & \\
\hline
\end{tabular}

Abbreviation: CMV: Cytomegalovirus.

Table 3: Prevalence of CMV co-infection in HIV-infected patients according to CD4+ T cell counts.

these patients were categorized into four groups according to absolute CD4 T cell count and CD4 T cell nadir count. We observed a significant difference between the groups.

\section{Factors associated with the prevalence of CMV in HIV in- fected patients}

Univariate analysis showed a significant relationship between the prevalence of CMV in HIV-infected patients and younger age, (age $<30$ years versus age $>40$ years, OR $2.777,95 \%$ CI 1.709-4.512, $\mathrm{P}<0.001$; age $30-40$ versus age $>40$ years, OR 5.320, $95 \%$ CI $3.335-8.487, \mathrm{P}<0.001)$, Treatment time of ART $(1$ year $\leq \mathrm{t}<1.5$ years versus $\mathrm{t}<0.5$ year, OR 1.886 , 95\% CI 1.148-3.098, $\mathrm{P}=0.012), \mathrm{CD} 4$ count cells/ $\mu \mathrm{l}$ (101-250 versus $<100$, OR $0.211,95 \%$ CI 0.116-0.384, $\mathrm{P}<0.001 ; 251-350$ versus $<100$, OR $0.036,95 \%$ CI $0.018-0.072, \mathrm{P}<0.001 ; \geq 351$ versus $<100$, OR 0.007 , 95\% CI 0.003-0.015, $\mathrm{P}<0.001)$ and CD4 nadir count cells/ $\mu \mathrm{l}(101-250$ versus $<100$, OR 0.026 , 95\% CI $0.015-0.045, \mathrm{P}<0.001 ; 251-350$ versus $<100$, OR $0.003,95 \%$ CI $0.001-0.012, \mathrm{P}<0.001 ; \geq 351$ versus $<100$, OR $0.001,95 \%$ CI $0-0.07, \mathrm{P}<0.001)$.

Multivariable logistic regression analysis indicated that, younger age (age 30-40 versus age $>40$ years, adjust OR 1.966 , 95\% CI 1.003-3.854, $\mathrm{P}=0.049)$, Treatment time of ART ( 1.5 years $\leq \mathrm{t}<2$ year versus $\mathrm{t}<0.5$ year, adjust OR 3.561, 95\% CI 1.631-7.776, $\mathrm{P}=0.001$; 1 year $\leq \mathrm{t}<1.5$ years versus $\mathrm{t}<0.5$ year, adjust OR 5.11,95\% CI 2.256-11.574, $\mathrm{P}<0.001 ; 0.5$ year $\leq t<1$ year versus $t<0.5$ year, adjust OR 3.119, 95\% CI 1.353-7.189, $\mathrm{P}=0.008)$, CD4 count cells/ $\mu \mathrm{l}(101-250$ versus $<100$, adjust OR 0.335 ,
95\% CI 0.156-0.721, $\mathrm{P}=0.005 ; 251-350$ versus $<100$, adjust $\mathrm{OR} 0.312$, $95 \%$ CI $0.117-0.827, \mathrm{P}=0.019 ; \geq 351$ versus $<100$, adjust $\mathrm{OR} 0.178,95 \%$ CI $0.066-0.479, \mathrm{P}=0.001)$ and $\mathrm{CD} 4$ nadir count cells $/ \mu \mathrm{l}$ (101-250 versus $<100$, adjust OR $0.033,95 \%$ CI $0.017-0.064, \mathrm{P}<0.001 ; 251-350$ versus $<100$, adjust OR $0.005,95 \% \mathrm{CI} 0.001-0.024, \mathrm{P}<0.001 ; \geq 351$ versus $<100$, adjust OR $0.002,95 \% \mathrm{CI} 0-0.016, \mathrm{P}<0.001$ ) are independent risk factors for the prevalence of CMV in HIV infected patients (Table 4).

\section{Discussion}

In this study, we report on the incidence and risk factors associated with HIV and CMV co-infection in Tianjin, using clinical data and stored blood samples for screening. Both HIV and CMV infections are independently associated with increased inflammation and inflammation-related morbidities [11]. Persistent co-infections likely contribute to overall immune dysfunction in HIV disease [12]. Therefore, the study of prevalence and risk factors in patients coinfected with HIV and CMV in Tianjin is warranted.

We found a high prevalence of CMV (12.8\%) in Tianjin HIVinfected patients starting ART. Our prevalence numbers are slightly lower than in reports from other settings. For example, Such as the prevalence in other high-income countries is between 15\% and 34\% [1315]. In our study, we found no association between CMV incidence and the timing of first-line ART, which implies that immune reconstitution does not provide significant protection against CMV. 
Citation: Jiang B, Su R, Zhang D, Gao L, Ma P, et al. (2018) Prevalence and Associated Factors of HIV and CMV Co-Infection in Tianjin, China. J AIDS Clin Res 9: 767. doi: 10.4172/2155-6113.1000767

Page 4 of 5

\begin{tabular}{|c|c|c|c|c|c|c|}
\hline & \multicolumn{3}{|c|}{ Univariable Analysis } & \multicolumn{3}{|c|}{ Multivariable Analysis } \\
\hline & Crude OR & $95 \% \mathrm{Cl}$ & p-Value & Adjusted OR & $95 \% \mathrm{Cl}$ & p-Value \\
\hline Male vs. Female & 0.453 & $(0.243-0.843)$ & 0.013 & 0.822 & $(0.282-2.400)$ & 0.720 \\
\hline \multicolumn{7}{|l|}{ Age } \\
\hline$<30$ years & 2.777 & $(1.709-4.512)$ & $<0.001$ & 1.728 & $(0.848-3.521)$ & 0.132 \\
\hline $30-40$ years & 5.320 & $(3.335-8.487)$ & $<0.001$ & 1.966 & $(1.003-3.854)$ & 0.049 \\
\hline$>40$ years & 1 & (reference) & & 1 & (reference) & \\
\hline \multicolumn{7}{|l|}{ Route of Infection } \\
\hline Heterosexual & 0.987 & $(0.314-3.104)$ & 0.982 & 1.354 & $(0.266-6.889)$ & 0.715 \\
\hline Homo/bisexual & 0.355 & $(0.115-1.097)$ & 0.072 & 0.924 & $(0.187-4.576)$ & 0.923 \\
\hline Intravenous drug use & 0.268 & $(0.027-2.696)$ & 0.264 & 1.132 & $(0.066-19.47)$ & 0.932 \\
\hline Other & 1.284 & $(0.401-4.107)$ & 0.674 & 0.916 & $(0.176-4.771)$ & 0.917 \\
\hline Unknown & 1 & (reference) & & 1 & (reference) & \\
\hline \multicolumn{7}{|l|}{ Treat Time } \\
\hline$T \geq 2$ years & 1.599 & $(0.805-3.174)$ & 0.180 & 2.477 & $(0.901-6.807)$ & 0.079 \\
\hline 1.5 years $\leq t<2$ years & 1.549 & $(0.949-2.529)$ & 0.080 & 3.561 & $(1.631-7.776)$ & 0.001 \\
\hline 1 year $\leq t<1.5$ years & 1.886 & $(1.148-3.098)$ & 0.012 & 5.111 & $(2.256-11.57)$ & $<0.001$ \\
\hline 0.5 year $\leq \mathrm{t}<1$ year & 1.318 & $(0.774-2.243)$ & 0.310 & 3.119 & $(1.353-7.189)$ & 0.008 \\
\hline$t<0.5$ year & 1 & (reference) & & 1 & (reference) & \\
\hline \multicolumn{7}{|l|}{ 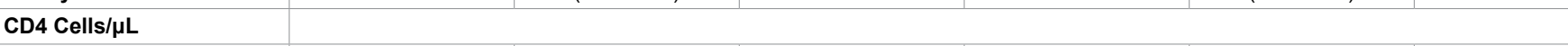 } \\
\hline$\leq 100$ & 1 & (reference) & & 1 & (reference) & \\
\hline $101-250$ & 0.211 & $(0.116-0.384)$ & $<0.001$ & 0.335 & $(0.156-0.721)$ & 0.005 \\
\hline $251-350$ & 0.036 & $(0.018-0.072)$ & $<0.001$ & 0.312 & $(0.117-0.827)$ & 0.019 \\
\hline$\geq 351$ & 0.007 & $(0.003-0.015)$ & $<0.001$ & 0.178 & $(0.066-0.479)$ & 0.001 \\
\hline \multicolumn{7}{|l|}{ CD4 Nadir Cells/ $\mu \mathrm{L}$} \\
\hline$\leq 100$ & 1 & (reference) & & 1 & (reference) & \\
\hline $101-250$ & 0.026 & $(0.015-0.045)$ & $<0.001$ & 0.033 & $(0.017-0.064)$ & $<0.001$ \\
\hline $251-350$ & 0.003 & $(0.001-0.012)$ & $<0.001$ & 0.005 & $(0.001-0.024)$ & $<0.001$ \\
\hline$\geq 351$ & 0.001 & $(0-0.007)$ & $<0.001$ & 0.002 & $(0.000-0.016)$ & $<0.001$ \\
\hline
\end{tabular}

Abbreviation: CMV: Cytomegalovirus; HIV: Human Immunodeficiency Virus.

Table 4: Logistic regression analyses of factors associated with HIV and CMV co-infection (compared with mono HIV-infected individuals).

The prevalence of CMV decreased with increasing CD4 counts. Interestingly, the prevalence is up to $68.8 \%-74.3 \%$ when $C D 4<100$ cells/ $\mu l$. As we know, CMV is a widespread $\beta$-herpesvirus that causes persistent infection. CMV seroprevalence can vary between $40 \%$ to $100 \%$ in the adult population depending on age, socioeconomic status and geographical region [16]. Primary CMV infection in immunocompetent hosts is often asymptomatic, but morbidity and mortality dramatically increase during immunodeficiency, particularly among transplant recipients and HIV-infected people [17].

We observed that the CD4 and CD4 nadir T cell count of patients were all associated with a higher risk of contracting CMV. This means CMV DNA quantitative assays should be used in HIV-infected patients for screening. The association between CMV viremia and increased mortality in HIV-infected patients, even in the context of ART, has also long been reported [18].

Several limitations of our study need to be acknowledged in our study. First, due to the nature of a single-center study, the results of this study might not necessarily represent the trend of CMV infection among all HIV-infected patients in Tianjin. Second, because this was an observational study, we selected a time period between January 2015 and December 2016. This means each patients had different follow-up and we only calculated the prevalence of CMV in HIV-infected patients in Tianjin during the study period. Therefore, CMV disease is likely to have been under-diagnosed in our study population.

Our study may nevertheless have significant implications for HIV care in Tianjin. The prevalence of CMV among HIV-infected patients was up to $68.7 \%$ with $\mathrm{CD} 4<100$ cells/ $\mu$ l. We suggest that CMV should be screened when $C D 4<250$ cells/ $\mu$ l, even if the patients do not have overt symptoms. A large-scale prospective study needs to be conducted to better document the extent of the problem of CMV in HIV-infected patients.

\section{Conclusion}

In conclusion, this study provides the prevalence of CMV in newly diagnosed HIV-infected patients who have undergone first-line ART in Tianjin between January 2015 and December 2016. We analyzed the associated factors of age, the time of first-line ART, CD4 count and CD4 nadir count. Finally, this study supports that CMV serological status should be taken into account when measuring the effectiveness of antiretroviral therapy on immune restoration and might have an impact on the effectiveness of future treatment approaches.

\section{Acknowledgement}

The authors thank all clinical staff at AIDS Clinical Center of Tianjin Second People's Hospital. We also thank all the participants of this study. This work was supported by Open subject of the State Key Laboratory for prevention and control of infectious diseases (2017SKLID314) and Tianjin Health and Family Planning Commission of Science and Technology Fund Key projects (2014KR03).

\section{References}

1. Griffiths P, Baraniak I, Reeves M (2015) The pathogenesis of human cytomegalovirus. J Pathol 235: 288-297.

2. Manicklal S, Emery VC, Lazzarotto T, Boppana SB, Gupta RK (2013) The "silent" global burden of congenital cytomegalovirus. Clin Microbiol Rev 26 : 86-102. 
Citation: Jiang B, Su R, Zhang D, Gao L, Ma P, et al. (2018) Prevalence and Associated Factors of HIV and CMV Co-Infection in Tianjin, China. J AIDS Clin Res 9: 767. doi: 10.4172/2155-6113.1000767

Page 5 of 5

3. Smith DM, Nakazawa M, Freeman M (2016) Asymptomatic CMV replication during early Human Immunodeficiency Virus (HIV) infection is associated with lower CD4/CD8 ratio during HIV treatment. Clin Infect Dis 63: 1517-1524.

4. Steininger C, Puchhammer-StockI E, Popow-Kraupp T (2006) Cytomegalovirus disease in the era of highly active antiretroviral therapy (HAART). J Clin Virol 37: 1-9.

5. Lichtner M, Cicconi P, Vita S, Lepri CA, Galli M, et al. (2015) Cytomegalovirus coinfection is associated with an increased risk of severe non-AIDS-defining events in a large cohort of HIV-infected patients. J Infect Dis 211: 178-186.

6. Poizot-Martin I, Allavena C, Duvivier C, Cano CE, Francine GS, et al. (2016) $\mathrm{CMV}+$ serostatus associates negatively with CD4: CD8 ratio normalization in controlled HIV-infected patients on CART. PLoS One 11: e0165774.

7. Hunt PW, Martin JN, Sinclair E, Epling L, Teague J, et al. (2011) Valganciclovir reduces $\mathrm{T}$ cell activation in HIV-infected individuals with incomplete CD4+ T cell recovery on antiretroviral therapy. J Infect Dis 203: 1474-1483.

8. Freeman ML, Mudd JC, Shive CL, Younes SA, Panigrahi S, et al. (2016) CD8 T-Cell expansion and inflammation linked to CMV co-infection in ART-treated HIV infection. Clin Infect Dis 62: 392-396.

9. Autran B, Carcelain G, Li TS, Blanc C, Mathez D, et al. (1997) Positive effects of combined antiretroviral therapy on CD4+ T cell homeostasis and function in advanced HIV disease. Science 277: 112-116.

10. Liu ZQ, Zhou N, Bai JY, Guo Y, Yu MH (2017) Analysis of survival and influencing factors of HIVIAIDS patients in Tianjin, 2004-2014. Zhonghua Liu Xing Bing Xue Za Zhi 38: 369-373.
11. Durier N, Ananworanich J, Apornpong T, Ubolyam S, Kerr SJ, et al. (2013) Cytomegalovirus viremia in Thai HIV-infected patients on antiretroviral therapy: Prevalence and associated mortality. Clin Infect Dis 57: 147-155.

12. Unemori P, Leslie KS, Hunt PW, Sinclair E, Epling L, et al. (2013) Immunosenescence is associated with presence of Kaposi's sarcoma in antiretroviral treated HIV infection. AIDS 27: 1735-1742.

13. Fishman JA (2013) Overview: Cytomegalovirus and the herpesviruses in transplantation. Am J Transplant 13: 1-8.

14. Erice A, Tierney C, Hirsch M, Caliendo AM, Weinberg A, et al. (2003) Cytomegalovirus (CMV) and Human Immunodeficiency Virus (HIV) burden, CMV end-organ disease and survival in subjects with advanced HIV infection (AIDS Clinical Trials Group Protocol 360). Clin Infect Dis 37: 567-578.

15. Deayton JR, Prof Sabin CA, Johnson MA, Emery VC, Wilson P, et al. (2004) Importance of cytomegalovirus viraemia in risk of disease progression and death in HIV-infected patients receiving highly active antiretroviral therapy Lancet 363: 2116-2121.

16. Gianella S, Massanella M, Wertheim JO, Smith DM (2015) The sordid affair between human Herpesvirus and HIV. J Infect Dis 212: 845-852.

17. Wohl DA, Zeng D, Stewart P, Glomb N, Alcorn T, et al. (2005) Cytomegalovirus viremia, mortality and end-organ disease among patients with AIDS receiving potent antiretroviral therapies. J Acquir Immune Defic Syndr 38: 538-544.

18. El Amari EB, Combescure C, Yerly S, Calmy A, Kaiser L, et al. (2011) Clinical relevance of cytomegalovirus viraemia. HIV Med 12: 394-402. 